\title{
DRYING CHARACTERISTICS OF MUSHROOMS
}

\author{
Tatjana Rubina, Aivars Aboltins \\ Latvia University of Life Sciences and Technologies, Latvia \\ tatjana.rubina@1lu.lv, aivars.aboltins@1lu.lv
}

\begin{abstract}
Mushrooms are delicious food with nutritional value, but extremely perishable and due to several physiological and morphological changes, which occur after harvest, become unacceptable for consumption. The most popular way to process mushrooms is drying. This research aims to investigate the drying characteristics of several typical types of common mushrooms. The objectives of the present study are: 1) to investigate the drying rate and diffusion coefficient variation; 2) to compare the drying characteristics of two methods of drying: forced convection drying and natural convection; 3) to compare the drying characteristics of forest mushrooms and mushrooms cultivated by artificial intensive methods. During this research two types of mushrooms growing in the wild and also mushrooms grown commercially and commonly available in shops have been investigated: Oyster mushroom (Pleurotus ostreatus), Portobello mushroom (Agaricus bisporus) and Red cracking bolete (Xerocomellus chrysenteron). These three types of mushrooms have been selected because they differ markedly by their structure, the conditions of the substrate on which they grow, and the verified results of the drying process. The drying process was determined gravimetrically at normal summer temperature about $28.7{ }^{\circ} \mathrm{C}$ and relative humidity of $43 \%$. The total drying time 25 hours was adapted to the need for determination of the lowest moisture content, which can be achieved by convective drying. The research results show that forced convection has a strong positive influence on the drying process comparing with drying by natural convection and reduces the time. The forced convection has significant impact on moisture removal only during the first 7 hours of the experiment. It is recommended to interrupt the air flow for the rest of drying, which allows optimizing the power consumption. Noticeable changes in thickness which decreases should be taken into account in diffusion coefficient determination.
\end{abstract}

Keywords: mushrooms, convective drying, diffusion coefficient, natural convection.

\section{Introduction}

Mushroom cultivation is the biggest biotechnology industry in the world that has great potential for the production of protein rich quality food and recycling of cellulose agro-residues, composted plant litter and waste products, which include straw, horse manure, gypsum, and wastewater. Global mushroom cultivation market accounted for $\$ 16.37$ billion in 2019 and is expected to reach 26.09 billion USD by 2027 [1].

There exist about 38000 varieties of mushrooms, while the most popular are Champignon mushrooms or Agaricus bisporus (whitebutton mushroom), Lentinus edodes (Shitake or Japanese mushroom), Pleurotus species (Oyster mushroom), Volvarella volvacea (paddy straw mushroom), Flammulna velutipes (winter mushroom) and the Auricularia polytricha (Jews'ear mushroom) [2].

Mushrooms are seasonal and highly perishable commodities that can only be maintained for few days. Due the highly perishable nature and commercial value of fresh mushrooms, they can be processed to extend their shelf life. Most popular preservations methods are drying, freezing, pickling, tincturing, canning and other methods. Freeze drying is recognized as the best method that can be used for mushroom drying in terms of final product quality, when compared to other existing drying methods, like sun solar drying, hot air drying, vacuum drying, etc.. But it is a very costly and time consuming process, while drying using heat is considered as a cost-effective method.

Dehydrated or dried mushrooms can be used for a wide range of applications as an important ingredient in several food formulations, for example, in soups, pasta salads, snack seasonings, stuffing, casseroles, and meat and rice dishes [3; 4]. Dried mushrooms can be further processed into powder and used in food processing as substitute for meat and for fortification of bakery products [5]. Experimental results have shown that dry matter is an important quality parameter, which content in mushrooms varies between 7 and 14\% [6], while the moisture content in dried mushrooms should be between 5 and $8 \%$ [2].

Drying is a complicated process with simultaneous heat and mass transfer, and food drying is especially a very complex process because of the differential structure of products [7]. There exist several drying methods: sun drying, tunnel drying, hot air drying, convection drying, microwavevacuum drying, mid-infrared-assisted convection drying, hot air coupled with radio frequency drying, 
and hot air coupled with microwave drying [8-11]. Drying mushrooms in the sun is not recommended due to its disruptive effect. It will almost certainly spoil the mushrooms [12]. Natural drying can be considered only for drying of small quantities [13].

Many studies have been previously performed on drying of different agricultural products and the undergoing processes. These studies have different directions. Some of them focus on the design of technical equipment $[14 ; 15]$, others investigate drying methods and their combinations $[2 ; 8-11 ; 16]$, examine the effect of different pre-treatment methods [16-18], investigate the influence of different drying parameters and conditions $[7 ; 12 ; 15 ; 19-25]$, and improve mathematical models [26-28].

It should be noted that in the vast majority of the performed research investigating drying kinetics, the authors consider parameters, such as moisture content or moisture ratio versus drying time, drying time, drying rate, rehydration ratio and the coefficient of rehydration, effective diffusion co-efficient, diffusivity constant and activation energy. The performed studies have not considered the diffusion coefficient. It is essential to have knowledge of the diffusion coefficient as a tool for mathematical modelling of mass transfer in mushroom drying.

This research aims to investigate the drying characteristics of wild forest mushrooms and mushrooms cultivated by artificial intensive methods. The objectives of the present study are: 1) to investigate the drying rate and diffusion coefficient variation; 2) to compare the drying characteristics of two methods of drying: forced convection drying and natural convection; 3 ) to compare the drying characteristics of forest mushrooms and mushrooms cultivated by artificial intensive methods.

\section{Materials and methods}

\section{Research object}

The research object of the current study is wild forest mushrooms Red cracking bolete (Xerocomellus chrysenteron) and mushrooms cultivated by artificial intensive methods, such as Oyster mushroom (Pleurotus ostreatus), Portobello mushroom (Agaricus bisporus). These types of mushrooms have been selected because of their differences by the structure, the conditions of the growing substrate, and the verified results of the drying process. Detailed description of laboratory measurements can be found in the study carried out by Kic [12].

Mushrooms were cut into $2 \mathrm{~mm}$ thin slices without applying any preparation methods and placed on sieve trays with mesh $3 \times 4 \mathrm{~mm}$ each type separately. Trays with samples were installed in each of three drying chambers, which allow independent measurements during drying at different flow rates of the drying air. The airflow was controlled by fan revolutions and delivered by the fan of $120 \mathrm{~mm}$ diameter.

\section{Experimental procedure and equipment}

In order to obtain experimental data, the mushroom samples were dried in a simple forced convection system [25] approximately for 25 hours at temperature about $28.7^{\circ} \mathrm{C}$ and relative humidity of $43 \%$. Low temperature was chosen as it is recommended for preservation of active ingredients in the product.

Within the study the drying characteristics were examined under two different drying conditions: the forced convection drying with the air velocity $1.2 \mathrm{~m} \cdot \mathrm{s}^{-1}$ and the natural convection drying with the same temperature and relative humidity with $0 \mathrm{~m} \cdot \mathrm{s}^{-1}$ air velocity.

During the experiments, measurements of the weight, air speed, air temperature and humidity were regularly performed at specified time intervals. Each measuring tray was weighed during the first 5 hours every $30 \mathrm{~min}$, later during the next period every $60 \mathrm{~min}$. Air temperature and humidity were measured by the sensor FHA646-E1C connected to the data logger ALMEMO 2690-8 [25]. The samples were weighed on the digital laboratory balance KERN-440-35N with resolution $0.01 \mathrm{~g}$.

After the experiment the mushroom samples were dried at temperature $105^{\circ}$ during the remainder of the experiment until they did not change the weight during an hour or until the drying experiment duration reached 25 hours in order to obtain dry matter. The drying experiment duration 25 hours was sufficient [6] for the maximal drop of the water content [12]. 


\section{Mathematical modelling}

Within this study the drying process characteristics from the experimental data are calculated, such as moisture concentration, removed moisture, drying coefficient versus drying time and moisture concentration, diffusion coefficient versus moisture concentration.

The experimental data sets from different drying experiments were expressed as the moisture concentration $\mathrm{C}$ versus the drying time $t$. The moisture concentration in $\%$ at a certain moment in time $t_{i}$ was calculated using the formula (1):

$$
C(\%)=\frac{M_{i}-M_{\infty}}{M_{0}-M_{\infty}} \cdot 100 \%,
$$

where $M_{i}-$ weight of the sample at time moment $t_{i}$, g;

$M_{\infty}$ - equilibrium weight of the sample, $\mathrm{g}$;

$M_{0}$ - weight of the sample before drying, $g$.

The normalized removed moisture in $\%$ at a certain moment in time $t_{i}$ was calculated using the formula (2):

$$
W(\%)=\frac{C_{0}-C_{i}}{C_{0}} \cdot 100 \%,
$$

where $C_{i}$ - moisture concentration at time moment $t_{i}, \%$;

$C_{0}$ - moisture concentration before drying.

The drying rate value $K\left(t_{i}\right)$ at certain moment in time $t_{i}$ was calculated using the formula (3) described by [29]:

$$
K\left(t_{i}\right)=-\frac{\ln \left(\frac{M_{i}-M_{\infty}}{M_{0}-M_{\infty}}\right)}{t_{i}} \cdot 100 \%
$$

where $t_{i}$-drying time, $\mathrm{h}$.

The diffusion coefficient value $D\left(t_{i}\right)$ at certain moment in time $t_{i}$ was calculated using simplified formula (4) $[24 ; 28]$ :

$$
D\left(t_{i}\right)=-\frac{K\left(t_{i}\right) \cdot L^{2}}{\pi},
$$

where $K\left(t_{i}\right)$ - drying coefficient at certain time moment $t_{i}, \mathrm{~h}^{-1}$.

\section{Results and discussion}

Two series of measurements concerning the drying of mushroom slices were taken: one with the drying process caused by natural convection with the air velocity $0 \mathrm{~m} \cdot \mathrm{s}^{-1}$, second - the drying process caused by forced convection with the air velocity $1.2 \mathrm{~m} \cdot \mathrm{s}^{-1}$.

For a shorter description of the experimental results, the mushrooms were marked in case of natural convection drying with air velocity $0 \mathrm{~m} \cdot \mathrm{s}^{-1}$ : Red cracking bolete (Xerocomellus chrysenteron, $\mathrm{X} 1$ ), Oyster mushroom (Pleurotus ostreatus, P1), Portobello mushroom (Agaricus bisporus, A1); in case of forced convection drying with air velocity $1.2 \mathrm{~m} \cdot \mathrm{s}^{-1}$ : Red cracking bolete (Xerocomellus chrysenteron, X2), Oyster mushroom (Pleurotus ostreatus, P2), Portobello mushroom (Agaricus bisporus, A2).

The evolution of removed moisture during the 25 hours of convection drying is given in Fig. 1 . The scattered points show the $\%$ of removed moisture of six samples. The experimental results show that forced convection (X2, P2, A2) reduces the drying time considerably. But it should be noted that a significant amount of moisture is removed in the first 7 hours. For the rest of the experiment the forced convection has insignificant impact on the drying process and is characterised by a linear relationship.

The evolution of the drying rate depending on the drying time during the 25 hours of convection drying is given in Fig. 2. In case of forced convection drying the drying rate decreases mostly linearly. Significantly different is the drying rate of mushrooms Oyster mushroom (Pleurotus ostreatus) as a 
result of the air influence. The first 5 hours of the experiment its values are higher in comparison with other types of mushrooms. In case of natural convection, the drying rate of all mushroom samples increases slow and has a linear character.

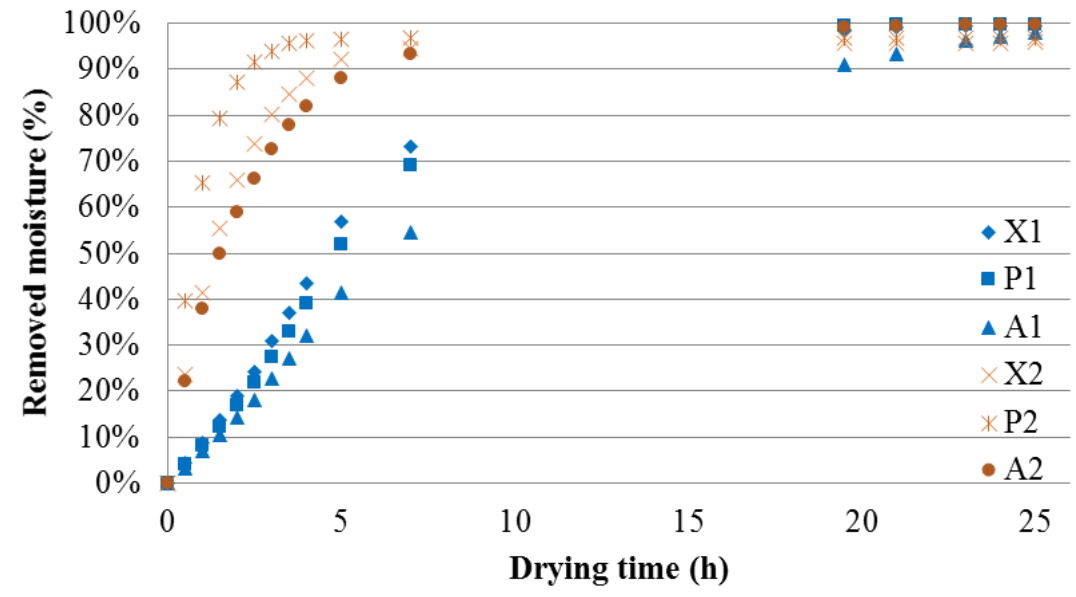

Fig. 1. Removed moisture dependence on the drying time of all 6 mushroom samples during the drying process with air velocities $0 \mathrm{~m} \cdot \mathrm{s}^{-1}(\mathrm{X} 1, \mathrm{P1}, \mathrm{A1})$ and $1.2 \mathrm{~m} \cdot \mathrm{s}^{-1}(\mathrm{X} 2, \mathrm{P} 2, \mathrm{A2})$



Fig. 2. Drying rate dependence on the drying time of all 6 mushroom samples during the drying process with air velocities $0 \mathrm{~m} \cdot \mathrm{s}^{-1}(\mathrm{X} 1, \mathrm{P1}, \mathrm{A1})$ and $1.2 \mathrm{~m} \cdot \mathrm{s}^{-1}(\mathrm{X} 2, \mathrm{P} 2, \mathrm{A2})$

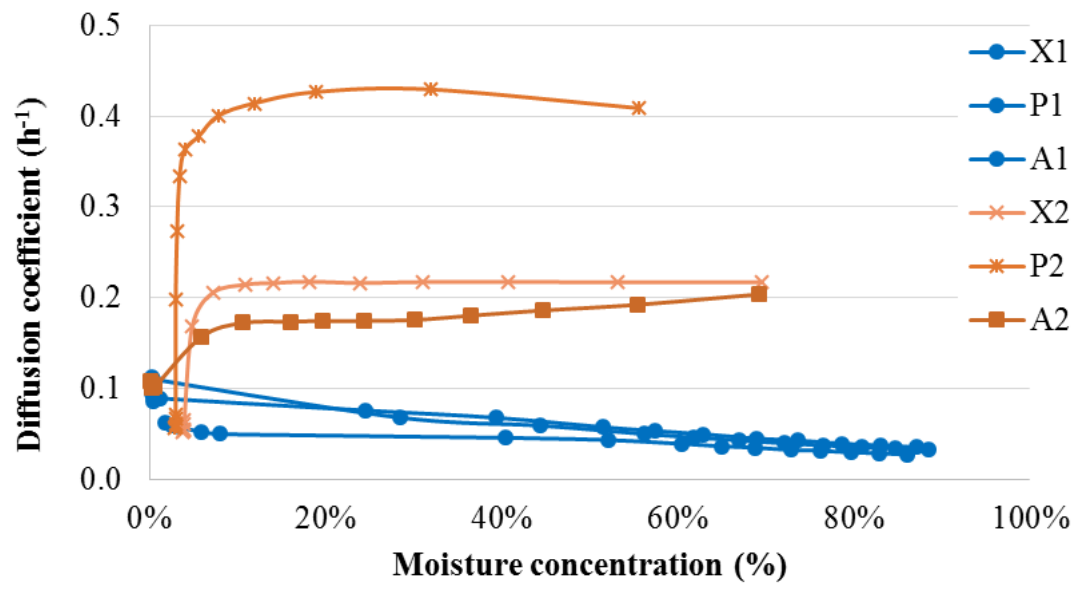

Fig. 3. Diffusion coefficient dependence on moisture concentration of all 6 mushroom samples during the drying process with air velocities $0 \mathrm{~m} \cdot \mathrm{s}-1$ (X1, P1, A1)

and $1.2 \mathrm{~m} \cdot \mathrm{s}^{-1}(\mathrm{X} 2, \mathrm{P} 2, \mathrm{~A} 2)$ 
Fig. 3 shows the dependence of the diffusion coefficient on moisture concentration during the 25 hours of convection drying. In case of convection drying during approximately the first 6 hours the diffusion coefficient remains almost unchanged, except for Oyster mushroom (Pleurotus ostreatus) sample where moisture concentration decreases until approximately to $7 \%$. Diffusion coefficient values of Oyster mushroom insignificantly increase during the first 2.5 hours of the drying experiment. But in the rest of the experiment the diffusion coefficient values decrease very rapidly. In case of natural convection, the diffusion coefficient increases slowly and strongly linearly.

The performed study results and calculations show that drying mushrooms under natural and forced convection, the diffusion coefficient remains constant and does not depend on the moisture concentration during the drying process. This can be explained by the porous structure of the material, where the internal moisture removal does not play a significant role. Drying of potatoes [22] shows similar results. Although the diffusion coefficient is linearly dependent on the moisture concentration, its dependence on the moisture concentration is insignificant.

\section{Conclusions}

1. The research results show that the forced convection has a strong positive influence on the drying process comparing with drying by natural convection and reduces the time of drying approximately four times.

2. The forced convection has significant impact on moisture removal only during the first 7 hours of the experiment. It is recommended to interrupt the air flow for the rest of drying, which allows optimizing the power consumption.

3. The diffusion coefficient remains constant and does not depend on the moisture concentration during the drying process that can be explained by the porous structure of the material.

4. The drying characteristics of Oyster mushroom differ noticeably from other types of mushrooms under consideration in case of forced convection drying. This type of mushroom should be studied more closely to determine the key factors which cause such differences.

5. During drying experiments could be discerned noticeable changes in the thickness which decreased. It should be taken into account in the diffusion coefficient determination.

\section{Acknowledgements}

The authors are very grateful to Professor Pavel Kic (Czech University of Life Sciences Prague) for the experimental data he provided.

\section{References}

[1] Mushroom Cultivation - Global Market Outlook (2019-2027). [online] [05.01.2021]. Available at: https://www.marketresearch.com/Stratistics-Market-Research-Consulting-v4058/MushroomCultivation-Global-Outlook-13866790/

[2] Balan N. and Radhakrishnan M. Microwave drying of edible mushroom. Mushroom Research 23 (1): 2014, pp. 81-87.

[3] Doymaz I. 2014. Drying Kinetics and Rehydration Characteristics of Convective Hot-Air Dried White Button Mushroom Slices. Journal of Chemistry, 2014, 8 p.

[4] Arumuganathan T., Manikantan M.R., Rai R.D., Anandakumar S., and Khare V. Mathematical modeling of drying kinetics of milky mushroom in a fluidized bed dryer. International Agrophysics Vol. 23(1), 2009, pp. 1-7.

[5] Das I., Arora A. Alternate Microwave and Convective Hot Air Application for Rapid Mushroom Drying. Journal of Food Engineering Vol. 223, 2017, pp. 208-219.

[6] Van Loon P.C.C., Swinkels H.A.T.I., and Van Griensven L.J.L.D. Dry matter content in mushrooms (Agaricus bisporus) as an indicator for mushroom quality. Science and Cultivation of Edible Fungi, Van Griensven (ed.). Balkema, Rotterdam, 2000, pp. 507-513.

[7] Mihalcea L. I., Bucur F. C., Mihaela A., Cantaragiu M., Gurgu L. C., Borda D. D., and Iordachescu G.S. Temperature influence on the agaricus bisporus mushrooms dehydration process. Scientific Study \& Research. Chemistry \& Chemical Engineering, Biotechnology, Food Industry Vol. 17(4), 2016, pp. 323-333. 
[8] Kḷava D., Kampuse S., Tomsone L., Kince T. and Ozola L. Effect of drying technologies on bioactive compounds maintenance in pumpkin by-products. Agronomy Research Vol. 16(4), 2018, pp. 1728-1741.

[9] Ozola L. and Kampuse S. The influence of drying method to the changes of bioactive compounds in lingonberry by-products. Agronomy Research Vol. 16(4), 2018, pp. 1781-1795

[10] Wang H., Zhang M., and Mujumdar A.S. Comparison of Three New Drying Methods for Drying Characteristics and Quality of Shiitake Mushroom (Lentinus edodes). Drying Technology Vol. 32, 2016, pp. 1791-1802.

[11] Martinez-Soto G., Torres-Reyes E., and Bautista-Justo M. Drying of Pleurotus ostreatus mushrooms by sun drying and tunnel drying. In: Proceedings of the second inter-american drying conference "2nd Inter-American Drying Conference (IADC)", 2001, July 8-10, Boca del Rio, Mexico, pp. 299-305.

[12] Kic P. 2018. Mushroom drying characteristics and changes of color. In: Proceeding of the International Scientific Conference Engineering for Rural Development, Latvia University of Life Sciences and Technologies, Jelgava, Latvia, 2018, pp. 432-438.

[13] Aboltins A. and Kic P. Research in some medical plant drying process. In: Proceeding of the International Scientific Conference Engineering for Rural Development, Latvia University of Life Sciences and Technologies, Jelgava, Latvia, 2016, pp. 1145-1150.

[14] Rybka A., Heřmánek P., and Honzík I. Effect of rotors on the parameters of hop drying in belt dryers. Agronomy Research Vol. 17(3), 2019, pp. 806-815.

[15] Heřmánek P., Rybka A. and Honzík I. Experimental chamber dryer for drying hops at low temperatures. Agronomy Research Vol. 15(3), 2017, pp. 713-719

[16] Moghanaki, S., Khoshandam, B. and Mirhal, M. Calculation of moisture content and drying rate during microwave drying. Applied Mechanics and Materials Vol. 423, 2013, pp. 746-749.

[17]Forouzanfar A., Hojjati M., Noshad M. and Szumny A. Influence of UV-B Pretreatments on Kinetics of Convective Hot Air Drying and Physical Parameters of Mushrooms (Agaricus bisporus). Agriculture Vol. 10(2): 371, 2020, $10 \mathrm{p}$.

[18] Ahmed N., Singh J., Chauhan H., Gupta P., Anjum A. and Kour H. Different drying methods: their applications and recent advances. International Journal of food nutrition and safety Vol. 4(1), 2013, pp. 34-42.

[19] Mizera Č., Herák D. and Hrabě P. Mathematical model describing the drying curves of false banana's fibre (Ensete ventricosum). Agronomy Research Vol. 15(S1), 2017, pp. 1094-1100.

[20] Wasserbauer M., Herak D., Mizera C., and Hrabe P. 2019. Utilization of image analysis for description of drying characteristics of selected tropical fruits. Agronomy Research Vol. 17(S2), 2019, pp. 1495-1500.

[21] Shete Y.V., More M.M., Deshmukh S.S. and Karne S.C. 2015. Effects of pre-treatments and drying temperatures on the quality of dried green peas. International Journal of Agricultural Engineering Vol. 8(2), 2015, pp. 220-226.

[22] Rubina T., Aboltins A., Palabinskis J. and Jasinskas A. Potatoes drying dynamics research. In: Proceeding of the International Scientific Conference Engineering for Rural Development, Latvia University of Life Sciences and Technologies, Jelgava, Latvia, 2016, pp. 187-192.

[23] Rubina T., Aboltins A., Palabinskis J. and Jotautiene. Study of drying and rehydration kinetics of carrot cylinders. In: Proceeding of the International Scientific Conference Engineering for Rural Development, Latvia University of Life Sciences and Technologies, Jelgava, Latvia, 2018, pp. 1488-1493.

[24] Rubina T., Aboltins A., and Palabinskis J. Drying characteristics of rhubarb cubes at low temperature. In: Proceeding of the International Scientific Conference Engineering for Rural Development, Latvia University of Life Sciences and Technologies, Jelgava, Latvia, 2019, pp. 1249-1256.

[25] Kic P. and Aboltins A. Convective drying of poultry manure by different air speeds. In: Proceeding of the International Scientific Conference Engineering for Rural Development, Latvia University of Agriculture, Jelgava, Latvia, 2013, pp. 121-125.

[26] Aboltins A., Rubina T., and Palabinskis J. Shrinkage effect on diffusion coefficient during carrot drying. Agronomy Research Vol. 16(S2), pp. 1301-1311. 
[27] Aboltins A., Palabinskis J., and Vartukapteinis K. Studies of berry drying process in infrared film dryer In: Proceeding of the International Scientific Conference Engineering for Rural Development, Latvia University of Agriculture, Jelgava, Latvia, 2017, pp.1515-1520.

[28] Hassini L., S. Azzouz S., and Belghith A. Estimation of the moisture diffusion coefficient of potato during hot-air drying. In: Proceedings of the 14th International Drying Symposium (IDS 2004), São Paulo, Brazil, Vol. B, 22-25 August, pp. 1488-1495.

[29] Aboltins, A. Theoretical study of material drying coefficient. In: Proceedings of International Scientific Conference Engineering for Rural Development, Latvia University of Agriculture, Jelgava, Latvia, 2013, pp. 153-158. 